\title{
REFLEXOS DOS TEMPOS DE COZIMENTO SOBRE A QUANTIDADE DE AÇÚCARES OBTIDOS DE GRÃOS DE MILHO DE 2,36mm
}

\author{
G. U. ALCANTARA ${ }^{1}$, L. C. NOGUEIRA ${ }^{1}$; S. M. MOYA ${ }^{1}$ e G. H. G. COSTA $^{1}$ \\ ${ }^{1}$ Centro de Ciências Sociais e Aplicadas - Universidade do Sagrado Coração \\ E-mail para contato: gigioalcantara@hotmail.com
}

\begin{abstract}
RESUMO - No decorrer dos anos o Brasil tem buscado diversas alternativas para a obtenção do etanol, para suprir a crescente demanda interna e externa pelo produto. Neste contexto, na busca por alternativas que possam ser incorporadas à produção deste biocombustível obtido a partir da cana-de-açúcar, destaca-se o milho, o qual tem a possibilidade de ser cultivado em locais de renovação de canaviais e serem processados na entressafra da cana. Embora essa tecnologia esteja em utilização no país, o setor ainda carece de algumas informações, como o tempo ideal de cozimento. Com isso, o objetivo deste trabalho foi de avaliar as características dos mostos de milho com granulometria de $2,36 \mathrm{~mm}$, submetidos a diferentes tempos cozimento. $O$ delineamento experimental utilizado foi inteiramente casualizado, com três tratamentos e três repetições. Os grãos foram triturados até granulometria de $2,36 \mathrm{~mm}$ e misturados com água na proporção $200 \mathrm{~g} / \mathrm{L}$. A seguir foram submetidos aos tempos de cozimento de 60, 90 e 180 minutos. As pastas foram resfriadas até $80-90^{\circ} \mathrm{C}$, e mantidas sob agitação constante. Nessa etapa adicionou-se a enzima $\alpha$-amilase. As pastas foram peneiradas e submetidas às análises de Brix, Açúcares Redutores Totais, Amido e $\mathrm{pH}$. Observou-se que quanto maior o tempo de cozimento, maior a concentração de açúcares e amido na pasta. Entretanto essas podem ser decorrentes da concentração resultante da evaporação de água. Portanto, conclui-se que o tempo de 60 minutos é recomendado para extrair açúcares do milho.
\end{abstract}

\section{INTRODUÇÃO}

Com a crescente demanda por matrizes energéticas mais sustentáveis, diversos países têm aderido à substituição parcial de combustíveis fósseis ou pela complementação das fontes energéticas anteriores através de alternativas que acompanhem a crescente demanda por fontes renováveis de energia.

Dentre essas alternativas, o etanol tem sido amplamente produzido e associado à matriz energética dos países, podendo destacar o Brasil e Estados Unidos como grandes produtores, consumidores e exportadores do biocombustível, utilizando-o a mais de 40 anos como complemento a gasolina em veículos leves. Deve-se destacar que o Brasil é pioneiro na produção de etanol através da cultura da cana-de-açúcar, produzindo o etanol anidro para misturar à gasolina na proporção de 27\% (AMATO; MATOSO, 2015) ou etanol hidratado na queima direta em motores de combustão interna. 
Para a safra de cana-de-açúcar 2016/2017, estima-se uma produção de aproximadamente 11,3 bilhões de litros de etanol anidro e 16,5 bilhões de litros de etanol hidratado no Brasil (CONAB, 2016), colocando o país como segundo maior produtor mundial do combustível, sendo superado apenas pelos Estados Unidos, o qual se tem a projeção de produzir 56,78 bilhões de litros de etanol extraído através do milho para a mesma safra (GLOBO RURAL, 2016).

Cabe destacar ainda que nos últimos 10 anos, a quantidade veículos movidos por este biocombustível no Brasil cresceu em 20 milhões, com uma oferta de etanol a qual cresceu de 17,8 para 27,8 bilhões de litros. Desta maneira, pode-se inferir que há um descompasso entre a oferta e a demanda por etanol, refletindo em elevações no preço final para o consumidor (UNICA, 2017).

Assim, faz-se necessário o aumento de produção, seja através da instalação de novas áreas de cana-de-açúcar, ou ainda a utilização de novas matérias-primas. Entre essas, destacase o milho, que por apresentar ciclo vegetativo de 120 dias, pode ser cultivado em áreas de renovação de canaviais (MAGALHÃES; DURÃES, 2006). Como não há necessidade de processamento após sua colheita, o milho pode ser armazenado em silos e processados no período da entressafra da cana, período o qual ocorre na região centro-sul do Brasil entre os meses de dezembro e março (SANTOS, 2006).

Atualmente há usinas instaladas nos estados de Goiás, Mato Grosso e Mato Grosso do Sul que processam o milho para produção de etanol em parques industriais dedicados, ou ainda em processamento conjunto com a cana-de-açúcar em unidades denominadas "usinas flex" (CHERUBIN, 2015).

Embora o processo já esteja em vigência no país, ainda há etapas do processo que podem ser otimizadas como, por exemplo, o tempo de cozimento necessário quando se processa grãos de elevada granulometria (acima de $2 \mathrm{~mm}$ ). Desta maneira, o objetivo do trabalho foi avaliar as características dos mostos de milho de granulometria $2,36 \mathrm{~mm}$.

\section{MATERIAL E MÉTODOS}

O experimento foi realizado no Laboratório de Biomassa e Bioenergia da Universidade do Sagrado Coração (USC), localizado no município de Bauru-SP. O milho foi obtido de pontos comerciais e unidades produtoras da região de Bauru-SP. O delineamento experimental foi inteiramente casualizado com 3 tratamentos e 3 repetições. Os tratamentos foram representados pelos tempos de cozimento de 60, 90 e 180 minutos.

Para a obtenção da granulometria de 2,36mm, os grãos de milho foram submetidos a um triturador de potência de $1,5 \mathrm{cv}-60 \mathrm{~Hz}$ e posteriormente um sistema de peneiras de $187 \mathrm{~W}-$ $50 / 60 \mathrm{~Hz}$.

A seguir, os grãos foram misturados com água acidulada ( $\mathrm{pH} 5,0-5,5)$, na proporção de 200g/L. Na sequência, os mesmos foram dispostos em recipientes de aço inox e submetidos a aquecimento/cozimento, mantidos em ebulição por 60, 90 e 180 minutos. Após cozimento, as amostras foram resfriadas a $80-90^{\circ} \mathrm{C}$, adicionando-se enzima $\alpha$-amilase $(300 \mathrm{KNU} / \mathrm{g})$. Nestas condições, a pasta de milho permaneceu por 30 minutos em agitação constante, para hidrólise 
do amido. A seguir, as amostras foram resfriadas a temperatura ambiente, peneiradas (Sistema de peneiras de $180 \mathrm{~W}-50 / 60 \mathrm{~Hz}$ - peneiras 3 e 2,36mm), e caracterizadas quanto ao Brix (refratômetro portátil), pH (CTC, 2005), Açúcares Redutores Totais (ART) (MILLER et al., 1959) e Amido (CHAVAN et al., 1991).

Para quantificação do ART, diluiu-se a pasta até que a concentração de açúcares (glicose) atingisse de $0,1 \mathrm{a} 1 \mathrm{~g} / \mathrm{L}$, sendo posteriormente, medido em $1 \mathrm{~mL}$ da amostra e dosado $1 \mathrm{~mL}$ do reagente de DNS (ácido dinitrosalicílico). A seguir, a reação entre o ácido e os açúcares ocorria por 6 minutos, dentro de um tubo de ensaio, no banho-maria em ebulição. As amostras foram resfriadas a temperatura ambiente, adicionados $8 \mathrm{~mL}$ de água destilada e foi realizada a leitura em espectrofotômetro em absorbância de 546nm (MILLER et al., 1995).

Considerando-se a análise de amido da pasta, diluiu-se a amostra até concentração de 0,1 a $1 \mathrm{~g} / \mathrm{L}$ de amido. Pipetou-se $1 \mathrm{~mL}$ da amostra, $1,2 \mathrm{~mL}$ de ácido acético $2 \mathrm{~N}, 0,25 \mathrm{~mL}$ de iodeto de potássio $10 \%$ e $2,5 \mathrm{~mL}$ de iodato de potássio $0,0017 \mathrm{~mol} / \mathrm{L}$. A leitura foi realizada em espectrofotômetro em absorbância de 570nm (CHAVAN et al., 1991).

Os resultados foram analisados pelo teste $\mathrm{F}$, e as médias comparadas segundo teste de Tukey (5\%) (BARBOSA; MALDONADO JUNIOR, 2015).

\section{RESULTADOS E DISCUSSÕES}

Na Tabela 1 estão apresentados os valores médios obtidos para Brix, ART, Amido e pH de grãos de milho submetidos a diferentes tempos de cozimento.

Tabela 1 - Valores médios obtidos para Brix, Açúcares Redutores Totais (ART), Amido e pH de grão de milho de $2,36 \mathrm{~mm}$, submetidos a cozimento por 60,90 e 180 minutos

\begin{tabular}{|c|c|c|c|c|}
\hline Tratamentos & Brix $\left(^{\circ}\right)$ & ART $(\%)$ & Amido $(\%)$ & $\mathrm{pH}$ \\
\hline Tempo (min) & $5,08^{* *}$ & $2,06 \mathrm{~ns}$ & $23,38^{* *}$ & $0,38 \mathrm{~ns}$ \\
\hline 60 & $15,3 \mathrm{~B}$ & $12,75 \mathrm{~A}$ & $0,34 \mathrm{~B}$ & 5,8 \\
\hline 90 & $17,6 \mathrm{AB}$ & $14,09 \mathrm{~A}$ & $0,56 \mathrm{~A}$ & 5,8 \\
\hline 180 & $19,5 \mathrm{~A}$ & $15,26 \mathrm{~A}$ & $0,69 \mathrm{~A}$ & 5,9 \\
\hline DMS & 3,98 & 3,79 & 0,16 & 0,48 \\
\hline $\mathrm{CV}(\%)$ & 9,08 & 10,79 & 12,16 & 3,28 \\
\hline
\end{tabular}

Letras diferentes na mesma coluna indicam diferença significativa segundo o teste de Tukey $(5 \%)$. **significativo ao nível de $1 \%$ de probabilidade. DMS - Desvio Mínimo Significativo. CV - Coeficiente de Variação

Considerando-se o Brix, verificou-se que quanto maior o tempo de cozimento, maior foi à concentração de sólidos solúveis na pasta. Isto pode ser em decorrência da concentração de moléculas como aminoácidos, açúcares, proteínas, dentre outras, através da evaporação de água promovida por elevados tempos de cozimento. Porém, os valores de Brix os quais estão entre $15 \%$ e $19,5 \%$, apresentaram valores superiores aos indicadores do mesmo parâmetro para o caldo de cana-de-açúcar, devendo-se destacar os valores obtidos por Macri et al. (2014) e Faustino et al. (2014), os quais estão na ordem de 16\%, quando utilizaram-se da cana-deaçúcar como matéria-prima.

Analisando-se o teor de ART, observou-se que os tempos de cozimento não influenciaram sobre esse parâmetro. Deve-se considerar que a quantificação de ART pelo 
método de DNS determina apenas glicose e frutose (MILLER, 1959), podendo-se inferir que a enzima $\alpha$-amilase utilizada hidrolisou grande maioria do amido presente nas amostras do grão de 2,36 mm, cada qual com seus respectivos tempos de cozimento. Se comparados com os valores obtidos em mostos do caldo de cana, verificou-se que houve resultados similares, nos quais Macri et al. (2014) obteve valores de 13\% e Faustino et al. (2014) resultados da ordem de 15 a $16 \%$.

Deve-se destacar também o teor de amido encontrado nas amostras de milho. $\mathrm{O}$ comportamento para esse parâmetro foi similar ao obtido pelo Brix, ou seja, pode ter sido influenciado pela evaporação de água. Porém, deve-se ressaltar que mesmo o tempo de 60 minutos ter apresentado um indicativo menor de amido nas amostras, ainda é uma concentração significativa do mesmo, demonstrando que não houve a total hidrólise dessa molécula. Isto é decorrente da presença de amilopectina que apresenta ligações $\alpha 1-6$, as quais não são hidrolisadas pela enzima $\alpha$-amilase, sendo necessário a utilização da enzima amiloglucosidade. Este comportamento também foi determinado por Ferreira (2015), que utilizando os grãos de sorgo sacarino para produção de etanol, verificou a necessidade da utilização dessas duas enzimas para conversão completa do amido em glicose, que possibilitou aumento do rendimento fermentativo.

Portanto, para os valores de $\mathrm{pH}$, observou-se que não houve grandes variações segundo o seu tempo de cozimento, podendo considerar que para a granulometria utilizada, não haverá influência do tempo sobre o pH das amostras durante a hidrólise.

\section{CONCLUSÃO}

Desse modo, pode-se concluir que o cozimento de grãos de milho em granulometria de 2,36 mm, por 60 minutos, resulta em um mosto de elevada quantidade de açúcares, baixo teor de amido e menor gasto energético, em relação a cozimentos por maiores períodos de tempo.

\section{REFERENCIAS}

AMATO, F.; MATOSO, F. Mistura de etanol na gasolina sobe para $27 \%$ a partir de 16 de março. G1/ECONOMIA, 2016. Disponível em: <http://g1.globo.com/economia/noticia/2015/03/mistura-de-etanol-na-gasolina-sobe-para27partir-de-16-de-marco.html>. Acesso em: 18 mar. 2017.

BARBOSA, J.C.; MALDONADO JUNIOR, W. Experimentação Agronômica \& AgroEstat - Sistema para Análises Estatísticas de Ensaios Agronômicos. FUNEP: Jaboticabal, 2015.

CHAVAN, S. M.; KUMAR, A.; JADHAV, S. J. Rapid quantitative analysis of starch in sugarcane juice. International Sugar Journal, Glamorgan, v. 93, n. 107, 1991.

CHERUBIN, N. Usina dois em um. RPA News: cana \& indústria, Ribeirão Preto, Ed. 13, n. 169, p. 6-13. 2015.

CONAB - Companhia Nacional de Abastecimento (Brasil). Acompanhamento da safra brasileira: Cana-de-açúcar - Terceiro levantamento | Dezembro/2016. v.3. n.3. Brasília: 
Conab, 2016.

Disponível

em: <http://www.conab.gov.br/OlalaCMS/uploads/arquivos/16_12_27_16_30_01_boletim_cana_ portugues_-3o_lev_-_16-17.pdf $>$. Acesso em: 01 mar. 2017.

CTC - Centro de Tecnologia Canavieira. Manual de métodos de análises para açúcar. Piracicaba, Centro de Tecnologia Canavieira, Laboratório de análises, 2005. Disponível em CD ROM.

FAUSTINO, P. A. S.; CARVALHO, M. R.; TEIXEIRA, J. R.; GARBIN, J. R.; MADALENO, L. L.; FRIGIERI, M. C. Fermentação do mosto de caldo de cana clarificado submetido a radiação ultravioleta. Ciência \& Tecnologia, v.6, n.1, suplemento, 2014.

FERREIRA, O. E. Produção de etanol a partir de sorgo sacarino com tratamento enzimático. 2015. 79 f. Tese de doutorado, Faculdades Ciências Agrárias e Veterinárias, Universidade Estadual Paulista, Jaboticabal, 2015.

GLOBO RURAL. Futuro do etanol sob administração Trump ainda é incerto, diz banco. G1/ GLOBO RURAL, 2016. Disponível em: $<$ http://revistagloborural.globo.com/Noticias/Politica/noticia/2016/11/globo-rural-futurodoetanol-sob-administracao-trump-ainda-e-incerto-diz-banco.html>. Acesso em: 28 fev. 2017.

MACRI, R. C. V.; COSTA, G. H. G.; MONTIJO, N. A.; SILVA, A. F.; MUTTON, M. J. R. Moringa extracts used in sugar cane juice treatment and effects on ethanolic fermentation. African Journal of Biotechnology, v.13, n.42, 2014.

MAGAlHÃES, P. C.; DURÃES, F. O. M. Fisiologia da produção de milho. Circular Técnica. Sete Lagoas: Embrapa, 2006. Disponível em: <http://www.cnpms.embrapa.br/publicacoes/publica/2006/circular/Circ_76.pdf>. Acesso em: 01 mar. 2017.

MILLER, G. L. Use of de dinitrosalicylic acid reagent for determination of reducing sugar. Analytical Chemistry, v.31, n.3, 1959.

SANTOS, J. P. Controle de Pragas Durante o Armazenamento de Milho. Circular Técnica. Sete Lagoas: Embrapa, 2006. Disponível em: $<$ http://www.diadecampo.com.br/arquivos/materias/\%7BED78457F-F649-4A828C23B5E5B134C737\%7D_Circ_84.pdf>. Acesso em: 01 mar. 2017.

UNICA - União da Indústria de Cana-de-açúcar. Unicadata, 2017. Disponível em: <http://www.unicadata.com.br/>. Acesso em: 13 mar. 2017. 